\title{
"Did You Have A Nice Evening?" A Day-Level Study on Recovery Experiences, Sleep, and Affect
}

\author{
Sabine Sonnentag, Carmen Binnewies, and Eva J. Mojza \\ University of Konstanz
}

\begin{abstract}
In this study, the authors used a within-person design to examine the relation between recovery experiences (psychological detachment, relaxation, mastery experiences) during leisure time, sleep, and affect in the next morning. Daily survey data gathered over the course of 1 work week from 166 public administration employees analyzed with a hierarchical linear modeling approach showed that low psychological detachment from work during the evening predicted negative activation and fatigue, whereas mastery experiences during the evening predicted positive activation and relaxation predicted serenity. Sleep quality showed relations with all affective states variables. This study adds to research on job-stress recovery and affect regulation by showing which specific experiences from the nonwork domain may improve affect before the start of the next working day.
\end{abstract}

Keywords: recovery, affect, sleep, work-home interface

Employees' work and nonwork lives are closely related (Crouter, 1984; Ford, Heinen, \& Langkamer, 2007; Heller \& Watson, 2005). Affect experienced at home has implications for affect and engagement at work (Edwards \& Rothbard, 2000; Greenhaus \& Powell, 2006). For example, Rothbard (2001) reported that positive affect at home was positively related to work absorption (i.e., the intensity of focusing on work), particularly among women. Using experience sampling data, Williams and Alliger (1994) showed that affect experienced at home was related to affect subsequently experienced at work. Judge and Ilies (2004) found that affect experienced at home in the evening predicted affect in the next morning at work.

Despite this increasing empirical evidence that affect experienced at home matters for affect and behavior at work, very little is known about the predictors of affect at home. With respect to job-related affect and behavior, it is particularly important to examine experiences off the job that are related to affect experienced in the morning before the start of a new working day. Research on job-stress recovery (Geurts \& Sonnentag, 2006; Westman \& Eden, 1997) suggests that recovery experiences (i.e., experiences during leisure time that provide the opportunity to unwind from work) are crucial for a person's affective states. There

Sabine Sonnentag, Carmen Binnewies, and Eva J. Mojza, Department of Psychology, University of Konstanz, Konstanz, Germany.

This study is part of a larger research project funded by the German Research Community (DFG; So 295/4-1). This grant is gratefully acknowledged. We thank Claudius Bornemann, Julia Meyer-Schwickerath, Christian Peters, and Signe Seiler for their invaluable support during data collection; Ines Spitzner for providing supplementary information when preparing the article; and Charlotte Fritz, Jana Kühnel, Jennifer Sparr, and Anne Spychala for helpful comments on earlier versions of this article.

Correspondence concerning this article should be addressed to Sabine Sonnentag, Department of Psychology, University of Konstanz, Postbox D42, D-78457, Konstanz, Germany. E-mail: sabine.sonnentag@unikonstanz.de is first empirical evidence that recovery experiences are related to affect at bedtime (e.g., Sonnentag \& Zijlstra, 2006). Affect at bedtime, however, might not be relevant for on-the-job behavior, as good sleep during the night might compensate for poor recovery during the evening. To the best of our knowledge, empirical research has not yet addressed the question of whether morning affect benefits from recovery experiences, such as relaxing and temporarily switching off from work while being at home.

Our study aims at examining off-job experiences (i.e., recovery experiences and sleep quality) that help persons to recuperate and unwind from work. Our study extends knowledge on job-stress recovery and affect regulation (Sonnentag \& Zijlstra, 2006; Thayer, Newman, \& McClain, 1994) by examining recovery experiences and sleep as predictors of morning affect. We use a within-person study design to capture daily fluctuations in recovery experiences, sleep, and affect. With our approach, we expect to gain a deeper insight into the sources of variation in day-to-day affect. In terms of practical applications, our study has implications for affect regulation. It provides information about how persons can spend their off-job time in a way that fosters favorable affective states that might spill over into work affect and behavior.

\section{Affective States}

Following Watson's conceptualization of affect, we examined positive and negative activation as two higher order dimensions, and serenity and fatigue as specific other affective states (Watson \& Clark, 1994; Watson, Wiese, Vaidya, \& Tellegen, 1999). Positive activation - as a state of high positive affect and high arousal-is characterized by a state of feeling active, strong, and delighted. Negative activation — as a state of high negative affect and high arousal-implies feeling tense, distressed, and angry. Serenity describes a state of being calm, relaxed, and at ease. Similar to positive activation, it is a state characterized by positive affect (i.e., pleasure; Russell, 1980; Russell \& Carroll, 1999) but with a lower level of arousal. Fatigue refers to feelings of tiredness and exhaustion. It tends to be a state of negative affect (i.e., displeasure; 
Russell, 1980; Russell \& Carroll, 1999) and is characterized by low arousal.

Research has shown that the negative versus positive affective systems correspond to distinct physiological processes (Cacioppo \& Gardner, 1999; Watson et al., 1999) and are influenced by distinct events and experiences (Kanner, Coyne, Schaefer, \& Lazarus, 1981; Watson, 1988). Specifically, Gable, Reis, and Elliot (2000) argued that positive events are related to positive affect, whereas negative events are related to negative affect.

\section{Recovery Experiences}

Recovery is an important concept in the context of job stress and strain. Generally, it is assumed that the process of working, particularly in the presence of stressors, causes strain reactions, such as fatigue or low positive affect (Fuller et al., 2003; Totterdell, Wood, \& Wall, 2006; Zohar, Tzischinski, \& Epstein, 2003). Recovery refers to processes opposite to such strain processes and becomes evident in the reduction or elimination of strain reactions. Authors have also described recovery processes as unwinding processes (Frankenhaueser \& Johansson, 1986), recuperation (Strauss-Blasche, Ekmekcioglu, \& Marktl, 2000), or restoration (Hartig, Evans, Jamner, Davis, \& Gärling, 2003).

Recovery occurs during time periods when no demands similar to the preceding job demands are put on the person (Meijman \& Mulder, 1998) or when new resources, such as energy or feelings of control, are built up (Hobfoll, 1998). Typically, recovery takes place during rest breaks at work (Trougakos, Beal, Green, \& Weiss, in press), free evenings (Rook \& Zijlstra, 2006), weekends (Fritz \& Sonnentag, 2005), or vacations (Westman \& Eden, 1997).

Sonnentag and Fritz (2007) used the term recovery experiences to characterize attributes associated with off-job activities contributing to recovery. These recovery experiences are very similar to affect-regulation strategies (Parkinson \& Totterdell, 1999; Thayer et al., 1994) and comprise experiences such as psychological detachment from work, relaxation, and the experience of mastery. We propose that these recovery experiences are related to subsequent affective states. As negative versus positive events and experiences are differentially associated with negative versus positive affect (Gable et al., 2000; Watson, 1988), we propose that a lack of psychological detachment from work (a negative experience) is related to negative activation and fatigue, and that relaxation and mastery (positive experiences) are related to positive activation and serenity. Affective reactions to recovery experiences may be immediate but will also persist over some time. Here, we focus on the relation between recovery experiences in the evening and subsequent morning affect.

\section{Psychological Detachment From Work}

Psychological detachment from work refers to an "individual's sense of being away from the work situation" (Etzion, Eden, \& Lapidot, 1998, p. 579). Psychological detachment implies not only to be physically absent from the workplace and to refrain from job-related tasks but also to stop thinking about job-related issues or problems (Sonnentag \& Bayer, 2005). As work is often associated with the experience of job stressors and is likely to result in negative activation and fatigue (Zohar et al., 2003), psychological detachment implies to gain distance from the events and experi- ences that caused this increase in negative affect. Lack of psychological detachment during after-work hours, however, means to remain cognitively occupied with stressful events experienced at work. During this continued preoccupation with work-related events and experiences, no recovery can occur (Meijman \& Mulder, 1998), and the strain process will continue. In other words, when not detaching fully, stressors may remain mentally present, and as a consequence, negative activation and fatigue will increase (Watson, 1988).

Research indicates that employees who psychologically detach themselves from work during off-job time and refrain from negative thoughts about their work experience less psychological (Fritz \& Sonnentag, 2006; Sonnentag \& Fritz, 2007) and physiological (Brosschott, Gerin, \& Thayer, 2006) strain symptoms. Findings from day-level research suggest that on days when persons are successful in psychologically detaching themselves from work, they experience less fatigue at bedtime (Sonnentag \& Bayer, 2005). We assume that this negative relation between psychological detachment and negative affect is not limited to a person's affective state at bedtime but will also still be present in the next morning. Therefore, we hypothesize that psychological detachment from work during evening hours is negatively related to morning negative activation and morning fatigue (Hypothesis 1)

\section{Relaxation}

Relaxation is a process characterized by decreased sympathetic activation and becomes evident in a decrease in heart rate, muscle tension, and other indicators of activation (Benson, 1975). Relaxation is also positively associated with positive affect (Fredrickson, 2000; Stone, Kennedy-Moore, \& Neale, 1995). Deep physical and mental relaxation can be achieved by deliberately practicing relaxation techniques, such as progressive muscle relaxation (Jacobson, 1938), meditation (Grossman, Niemann, Schmidt, \& Walach, 2004), and other approaches aiming at the relaxation of body and mind (Sandlung \& Norlander, 2000). In everyday life, some degree of relaxation may also result from other activities that provide uplift experiences (Kanner et al., 1981), such as a light walk in a beautiful natural environment (Hartig et al., 2003) or listening to music (Pelletier, 2004)

Relaxation is a positive experience at the physical and mental level and should therefore be associated with positive affect (Fredrickson, 2000). Although research on relaxation as a stress intervention method has shown that in the long run relaxation techniques reduce tension (i.e., negative affect) and other symptoms of poor well-being (Van der Klink, Blonk, Schene, \& Van Dijk, 2001), day-level research suggests that in the short run particularly positive affective states increase after relaxation experiences (Stone et al., 1995). For example, Parkinson and Totterdell (1999) reported that engagement in relaxing activities predicted cheerfulness and calmness. Therefore, we hypothesize that relaxation during evening hours is positively related to morning positive activation and serenity (Hypothesis 2).

\section{Mastery Experiences}

Mastery experiences refer to challenging off-job experiences that provide opportunities for learning and success. Mastery experiences are accompanied by feelings of competence and profi- 
ciency and may result from activities such as sport, learning a new hobby, or engaging in volunteer work (Fritz \& Sonnentag, 2006; Ruderman, Ohlott, Panzer, \& King, 2002). Mastery experiences challenge the person without overtaxing his or her capabilities. Experienced competence and associated feelings of performing well constitute an uplift experience that will be associated with positive activation and serenity. Whereas relaxation promotes recovery by reducing demands and associated activation, mastery experiences have an impact on recovery by asking for some degree of effort investment.

Research focusing on between-persons differences showed that employees who experience mastery during their off-job time generally report better well-being and life satisfaction (Sonnentag \& Fritz, 2007). Studies taking a within-person perspective have demonstrated that engagement in sport and exercise-prototypical mastery activities - is related to improved positive affect (Sonnentag, 2001; Watson, 1988). We hypothesize that mastery experiences during evening hours are positively related to morning positive activation and serenity (Hypothesis 3 ).

\section{Sleep}

Not only are psychological detachment, relaxation, and mastery experiences associated with morning affect but sleep quality is as well. There is broad empirical evidence that poor sleep negatively influences affect (Pilcher \& Huffcutt, 1996). Studies that used between-persons designs showed relations between poor sleep quality and health complaints, tension, depressed mood, anger, and fatigue (Lavidor, Weller, \& Babkoff, 2003; Pilcher, Ginter, \& Sadowsky, 1997). Studies that used within-person analyses found that sleep quality predicted a range of positive and negative affect variables during the subsequent day (Scott \& Judge, 2006; Totterdell, Reynolds, Parkinson, \& Briner, 1994).

On the basis of this research, we propose that sleep quality is positively related to positive activation and serenity and negatively related to negative activation and fatigue experienced the next morning. There are several reasons for hypothesizing such relations. First, poor sleep quality may constitute a negative affective event in itself that triggers negative affect. Second, as poor sleep hinders replenishment of resources for self-regulation (Muraven \& Baumeister, 2000), persons have fewer resources available for affect regulation after a night of poor sleep. Therefore, distressing events encountered in the morning will more likely result in negative activation and fatigue because these events cannot be successfully counteracted by regulatory efforts. Similarly, energy resources will not be sufficient to capitalize on opportunities for goal enhancement, and as a consequence, positive affect will not increase (Zohar, Tzischinski, Epstein, \& Lavie, 2005). Third, beliefs and appraisals may influence affect (Harris \& Daniels, 2005). After a night of poor sleep, persons will anticipate problems in goal attainment (e.g., difficulties to concentrate) and the need to invest compensatory effort to attain their goals. Such an anticipation will increase negative affect and decrease positive affect. We hypothesize that sleep quality is positively related to morning positive activation and serenity (Hypothesis 4) and negatively related to morning negative activation and fatigue (Hypothesis 5).

\section{Control Variables}

In our analyses, we control for within-person and betweenpersons variables that might also have an impact on morning affect: affect experienced on the preceding day (i.e., autocorrelation of affect), daily hassles experienced in the evening (e.g., arguments with one's spouse or problems with the children), sleep duration, trait affect (i.e., a person's general tendency to experience certain affective states; cf. Fisher, 2002), gender, age, leadership position, and country of data collection.

\section{Method}

\section{Overview}

This study was part of a larger project on recovery during evening hours (Binnewies, Sonnentag, \& Mojza, 2006). Study participants filled in one general survey and completed daily surveys on handheld computers (Palm's [Sunnyvale, CA] Zire) over 5 consecutive working days (Monday-Friday). For this study, we linked daily survey data assessed at bedtime to daily survey data assessed the next morning before going to work.

\section{Procedure and Sample}

We conducted our study in German and Swiss public service organizations operating at the community level. To recruit study participants, we contacted site managers and informed them about our study. After managers expressed their organization's consent to participate, employees received information packages that included (a) a letter presenting the project as a study on "recovery from work-related stress" and describing the data collection procedure in general terms, and (b) a return form for registration. Upon registration, we sent the general survey to the participants and scheduled a week for collecting daily-surveys data with the handheld computers.

During face-to-face meetings, research assistants explained the functioning of the handheld computers to the participants and instructed them how and when to answer the daily surveys. To remind participants of completing the daily survey, we programmed alarms on the handheld computers that fit participants' personal daily schedules. To encourage participation, we promised feedback to the organizations and announced a lottery prize for participants.

In total, 203 persons from 36 public service organizations agreed to participate in our study and received a handheld computer to fill in daily surveys. Because of technical problems, 4 participants could not provide any daily survey data. General surveys were returned by 202 persons. General survey data and daily survey data could be matched for 192 persons.

Handheld computers recorded the time when participants answered daily surveys. A total of 26 persons missed daily surveys or answered them at wrong times (e.g., morning survey answered in the afternoon) and consequently were excluded from analyses. Overall, completion rates for morning surveys ranged from $75.5 \%$ to $91.7 \%(M=85.6)$ and for bedtime surveys days from $63.0 \%$ to $88.0 \%(M=80.8)$.

The final sample comprised 166 persons (62.7\% women). Average age was 38.64 years $(S D=10.73)$. Most participants $(67.1 \%)$ lived with a partner, and about a half of the participants 
(45.7\%) had children. Of the participants, $78 \%$ worked in Germany, and $22 \%$ worked in Switzerland. Participants' average tenure with their organizations was 9.73 years $(S D=8.11)$. Participants worked in a broad range of different public sector jobs, including civil servants in the local and financial administration of small towns and villages, chief officers of larger administrative units, social workers, support staff, and specialized professionals. About one third of the sample (35.5\%) had a leadership position. Our sample was fairly well trained, with $48.5 \%$ having completed 2-3 years of professional training and an additional $49.1 \%$ holding a university degree. We tested whether persons included in the final sample differed from those not included (e.g., because they did not complete the daily survey at the correct times). We did not find significant differences for any of our study variables between participants and nonparticipants.

\section{Measures}

We collected our data with a bedtime and a morning survey (both implemented on handheld computers) and with a general paper-based survey. At bedtime we assessed recovery experiences and daily hassles. In the morning we assessed sleep quality, sleep duration, and morning affect. Table 1 displays means, standard deviations, Cronbach's alphas, and correlations between the variables.

Recovery experiences. We assessed psychological detachment from work, relaxation, and mastery experiences in the bedtime survey with items adapted from the Recovery Experience Questionnaire (Sonnentag \& Fritz, 2007). Psychological detachment, relaxation, and mastery experiences were assessed with four 5-point Likert items each that referred to the experience during the specific evening (see the Appendix). To test whether these three recovery experiences represented distinct constructs, we ran a set of confirmatory factor analyses based on the person-mean centered data (cf. Bolger, Davis, \& Rafaeli, 2003). A three-factor model, $\chi^{2}(51)=274.36$, nonnormed fit index $(\mathrm{NNFI})=0.96$, comparative fit index $(\mathrm{CFI})=0.97$, root-mean-square error of approximation $($ RMSEA) $=0.075$, provided a better fit than a one-factor model, $\Delta \chi^{2}(3)=2887.07, p<.001$, and all possible two-factor models, $\Delta \chi^{2}(1) \geq 924.44, p<.001$.

Sleep quality. We assessed sleep quality in the morning survey with one single item derived from the Pittsburgh Sleep Quality Index (Buysse, Reynolds, Monk, Berman, \& Kupfer, 1989; "How do you evaluate this night's sleep?") on a 4-point Likert scale.

Morning affect. In the morning survey, we assessed positive activation, serenity, negative activation, and fatigue. Participants responded to all affect items on a 5-point Likert scale with respect to their state on the specific morning. We assessed positive activation with six positive affect items from the Positive and Negative Affect Schedule (PANAS; "active," "interested," "excited," "strong," "inspired," and "alert"; Watson, Clark, \& Tellegen, 1988), serenity with four items ("calm," "relaxed," "laid-back," and "placid") from a measure developed by Abele-Brehm and Brehm (1986), negative activation with six negative affect items from the PANAS ("distressed," "upset," "irritable," "nervous," "jittery," and "afraid"), and fatigue with four items from the Profiles of Mood Scales ("fatigued," "tired," "exhausted," "spent”;

Table 1

Means, Standard Deviations, and Correlations Between Study Variables

\begin{tabular}{|c|c|c|c|c|c|c|c|c|c|c|c|c|c|c|c|c|c|c|c|c|}
\hline Variable & $M$ & $S D$ & $\alpha$ & 1 & 2 & 3 & 4 & 5 & 6 & 7 & 8 & 9 & 10 & 11 & 12 & 13 & 14 & 15 & 16 & $17 \quad 18$ \\
\hline 1. Detachment & 3.84 & 0.84 & .90 & - & .38 & .19 & .16 & -.02 & .08 & .08 & .24 & -.22 & -.10 & & & & & & & \\
\hline 2. Relaxation & 3.06 & 0.87 & .83 & .49 & - & -.06 & .03 & -.20 & .08 & .10 & .21 & -.15 & -.05 & & & & & & & \\
\hline $\begin{array}{l}\text { 3. Mastery } \\
\text { experiences }\end{array}$ & 2.18 & 0.71 & .88 & .26 & .01 & - & .00 & .08 & -.00 & .11 & .12 & -.05 & -.09 & & & & & & & \\
\hline 4. Sleep quality & 2.11 & 0.61 & & .21 & .07 & -.00 & - & -.09 & .31 & .32 & .31 & -.32 & -.39 & & & & & & & \\
\hline 5. Daily hassles & 1.48 & 0.37 & .63 & .01 & -.19 & .16 & -.06 & - & -.04 & -.10 & -.16 & .20 & .13 & & & & & & & \\
\hline 6. Sleep duration & 6.66 & 1.01 & & .15 & .10 & -.06 & .33 & .04 & - & .18 & .19 & -.05 & -.17 & & & & & & & \\
\hline $\begin{array}{l}\text { 7. Morning positive } \\
\text { activation }\end{array}$ & 2.92 & 0.74 & .87 & .06 & .10 & .08 & .34 & -.11 & .01 & - & .62 & -.19 & -.63 & & & & & & & \\
\hline 8. Morning serenity & 3.29 & 0.69 & .83 & .33 & .25 & .19 & .41 & -.13 & .03 & .65 & - & -.42 & -.39 & & & & & & & \\
\hline $\begin{array}{l}\text { 9. Morning negative } \\
\text { activation }\end{array}$ & 1.22 & 0.28 & .82 & -.28 & -.20 & -.10 & -.35 & .19 & -.11 & -.26 & -.52 & - & .33 & & & & & & & \\
\hline 10. Morning fatigue & 1.82 & 0.71 & .88 & -.09 & -.08 & -.07 & -.26 & .15 & -.08 & -.68 & -.45 & .26 & - & & & & & & & \\
\hline $\begin{array}{l}\text { 11. Trait positive } \\
\text { activation }\end{array}$ & 3.46 & 0.59 & .77 & .05 & .12 & .10 & .21 & -.15 & .03 & .45 & .45 & -.25 & -.32 & - & & & & & & \\
\hline 12. Trait serenity & 3.17 & 0.70 & .78 & .10 & .15 & .16 & .10 & -.21 & -.01 & .24 & .43 & -.26 & -.31 & .58 & - & & & & & \\
\hline $\begin{array}{l}\text { 13. Trait negative } \\
\text { activation }\end{array}$ & 1.73 & 0.57 & .77 & -.12 & -.19 & -.06 & -.06 & .25 & .17 & -.17 & -.29 & .40 & .30 & -.30 & -.49 & - & & & & \\
\hline 14. Trait fatigue & 2.13 & 0.86 & .90 & -.04 & -.10 & -.23 & .01 & .31 & .16 & -.22 & -.19 & .16 & .41 & -.41 & -.56 & .60 & - & & & \\
\hline 15. Gender ${ }^{a}$ & 1.38 & 0.49 & & -.25 & -.09 & -.03 & -.09 & .01 & -.19 & .06 & .03 & -.03 & .02 & -.04 & -.03 & .05 & .04 & - & & \\
\hline 16. Age & 38.55 & 10.84 & & -.28 & -.12 & -.18 & -.15 & -.00 & -.30 & .14 & .03 & .10 & -.10 & .07 & -.02 & -.03 & -.02 & .30 & - & \\
\hline 17. Country ${ }^{\mathrm{b}}$ & 1.23 & 0.42 & & .02 & .01 & .02 & .07 & -.20 & .04 & .10 & .16 & -.04 & -.02 & .16 & .05 & -.00 & -.10 & -.02 & -.04 & - \\
\hline $\begin{array}{l}\text { 18. Leadership } \\
\text { position }^{\mathrm{c}}\end{array}$ & 1.36 & 0.48 & & -.31 & -.02 & -.20 & -.09 & -.05 & -.14 & .08 & .09 & .03 & .02 & .01 & -.09 & .07 & .10 & .48 & .40 & $.07-$ \\
\hline
\end{tabular}

Note. Cronbach's alpha for day-level variables are mean internal consistencies averaged over all measurement days. Correlations below the diagonal are person-level correlations $(N=166)$ with correlations $r \geq .16$ being significant at $p<.05$ and $r \geq .20$ being significant at $p<.01$. Correlations above the diagonal are day-level correlations $(N=441)$ with correlations $r \geq .09$ being significant at $p<.05$ and $r \geq .12$ being significant at $p<.01$. ${ }^{\mathrm{a}} 1$ = Female; 2 = Male. ${ }^{\mathrm{b}} 1$ = Germany; 2 = Switzerland. ${ }^{\mathrm{c}} 1=$ No leadership position; 2 = Leadership position. 
McNair, Lorr, \& Droppelman, 1971). To examine whether these four affect scales represented distinct constructs, we ran a set of confirmatory factor analyses conducted on the person-mean centered data in which we compared the four-factor model with alternative models. The four-factor model, $\chi^{2}(164)=756.16$, $\mathrm{NNFI}=0.94, \mathrm{CFI}=0.95$, RMSEA $=0.073$, showed a better model fit than a one-factor model, $\Delta \chi^{2}(6) \geq 1,312.33, p<.001$, all two-factor models, $\Delta \chi^{2}(5) \geq 666.20, p<.001$, and all threefactor models, $\Delta \chi^{2}(3) \geq 246.64, p<.001$.

Control variables at the day level. We assessed daily hassles during evenings and sleep duration as day-level control variables. We measured daily hassles in the bedtime survey with nine 5-point Likert items adapted from the measure developed by Bolger et al. (2003; e.g. "Today I had an argument with my spouse"). We gathered day-level sleep duration data in the morning survey by asking study participants about how many hours they had actually slept (as opposed to spending time in bed) during the last night.

Control variables at the person level. We assessed gender, age, leadership position, and country of data collection as personlevel control variables. We measured trait affect in the general survey with the same 5-point Likert-type items used in the daily survey, but we instructed participants to report how they felt "in general." Confirmatory factor analysis resulted in a better fit for a model comprising four distinct factors, $\chi^{2}(164)=327.63$, NNFI $=$ 0.94 , CFI $=0.94$, RMSEA $=0.078$, than a one-factor model, $\Delta \chi^{2}(6) \geq 325.85, p<.001$, and all possible two-factor models, $\Delta \chi^{2}(5) \geq 103.12, p<.001$, or three-factor models, $\Delta \chi^{2}(3) \geq$ 40.43, $p<.001$.

\section{Data Analysis}

We analyzed our data with a hierarchical linear modeling approach (Bryk \& Raudenbush, 1992; Snijders \& Bosker, 1999) using MLwiN software (Rasbash et al., 2000). We centered all day-level predictor and control variables (Level 1; e.g., recovery experiences) at the respective person mean (cf. Judge, Ilies, \& Scott, 2006), and person-level control variables (Level 2; e.g., trait affect) at the grand mean. Centering day-level variables at the person mean implies that all between-persons variance in these variables is removed, and interpretations of our results referring to stable differences between persons can be ruled out.

\section{Results}

\section{Preliminary Analyses}

Before testing our hypotheses, we examined whether morning affect differed within persons. Partitioning of the total variance into within- and between-persons variance showed that $46.7 \%$ of the total variance of positive activation was within persons. For serenity, negative activation, and fatigue, within-person variance was $51.4 \%, 84.3 \%$, and $57.9 \%$, respectively. Overall, these analyses show that a substantial portion of the variance in morning affect can be attributed to within-person variation.

\section{Test of Hypotheses}

For testing our hypotheses with nested hierarchical linear models, we started with an intercept-only model (null model). In Model 1 , we entered person-level control variables (gender, age, country, leadership position, and trait affect). The specific affect variable included was different according to the outcome variable examined. For example, when predicting positive activation, we entered the trait positive activation-assessed in the general survey-as the control variable. In Model 2, we included day-level control variables (autocorrelation of day-specific affect, daily hassles, and sleep duration). In Model 3, we entered the three recovery experiences (psychological detachment, relaxation, and mastery experiences) and sleep quality as our core predictor variables of interest. Tables 2,3,4, and 5 display model fit information (difference of $-2 \times \log$ ), estimates for the fixed parameters, and estimates for the variance components.

For morning positive activation as an outcome measure (see Table 2), Model 1, which included person-level control variables, showed a better model fit than the null model. Trait positive activation was a strong predictor of morning positive activation. Model 2 with the day-level control variables showed an improved fit over Model 1, with sleep duration positively predicting morning positive activation. Model 3, which included the recovery experience measures and sleep quality, showed an even better fit than Model 2. Significant predictor variables were mastery experiences and sleep quality. All predictor and control variables entered into the models explained $30.4 \%$ of the variance at Level $2(0.385-$ $0.268 / 0.385=0.304)$ and $20.0 \%$ of the variance at Level 1 $(0.275-0.221 / 0.275=0.20)$.

For morning serenity as an outcome variable (see Table 3), Model 1 showed a better fit than the null model. Country and a person's general level of serenity were significant predictors of morning serenity, with Swiss participants reporting higher serenity than German participants. The predictor variables entered in Model 2, particularly sleep duration, contributed to an increased model fit. Model 3 with recovery experiences and sleep quality as additional predictor variables fit the data better than Model 2 . Relaxation and sleep quality were both positively related to morning serenity. All predictor and control variables entered into the models explained $31.07 \%$ of the variance at Level 2 and $12.8 \%$ of the variance at Level 1 .

For morning negative activation as an outcome variable (see Table 4), Model 1, which included person-level control variables, showed a better fit than the null model, with trait negative activation being a strong predictor of morning negative activation. Model 2 did not show an improvement over Model 1. Model 3 fit the data better than Model 2, with low psychological detachment from work during evening hours and poor sleep quality predicting high morning negative activation. All predictor and control variables entered into the models explained $44.8 \%$ of the variance at Level 2 and $13.5 \%$ of the variance at Level 1 .

For morning fatigue as an outcome variable (see Table 5), Model 1 with the person-level predictor variables resulted in a better model fit than the null model. General level of fatigue was a strong predictor of morning fatigue. When entering day-level predictor variables into Model 2, model fit improved further, with sleep duration showing a strong negative relation with morning fatigue. Model 3, which included the three recovery experience measures and sleep quality, resulted in a better model fit. Low psychological detachment and poor sleep quality predicted morning fatigue. All predictor and control variables entered into the models explained $37.8 \%$ of the variance at Level 2 and $21.9 \%$ of the variance at Level 1. 
Table 2

Multilevel Estimates for Models Predicting Morning Positive Activation

\begin{tabular}{|c|c|c|c|c|c|c|c|c|c|c|c|c|}
\hline \multirow[b]{2}{*}{ Variable } & \multicolumn{3}{|c|}{ Null model } & \multicolumn{3}{|c|}{ Model 1} & \multicolumn{3}{|c|}{ Model 2} & \multicolumn{3}{|c|}{ Model 3} \\
\hline & Estimate & $S E$ & $t$ & Estimate & $S E$ & $t$ & Estimate & $S E$ & $t$ & Estimate & $S E$ & $t$ \\
\hline Intercept & 2.925 & 0.056 & 52.23 & 2.533 & 0.258 & 9.82 & 2.543 & 0.253 & 10.05 & 2.533 & 0.252 & 9.92 \\
\hline Gender & & & & 0.031 & 0.117 & 0.26 & 0.041 & 0.115 & 0.36 & 0.039 & 0.115 & 0.34 \\
\hline Age & & & & 0.006 & 0.005 & 1.20 & 0.005 & 0.005 & 1.00 & 0.006 & 0.005 & 1.20 \\
\hline Country & & & & 0.073 & 0.121 & 0.60 & 0.075 & 0.119 & 0.63 & 0.065 & 0.118 & 0.55 \\
\hline Position & & & & 0.045 & 0.124 & 0.36 & 0.033 & 0.122 & 0.27 & 0.043 & 0.121 & 0.35 \\
\hline Trait positive activation & & & & 0.563 & 0.085 & $6.62^{* * * *}$ & 0.555 & 0.093 & $5.97^{* * * *}$ & 0.555 & 0.092 & $6.85^{* * * *}$ \\
\hline $\begin{array}{l}\text { Positive activation previous } \\
\text { morning }\end{array}$ & & & & & & & 0.026 & 0.055 & 0.47 & 0.026 & 0.053 & 0.49 \\
\hline Daily hassles & & & & & & & -0.137 & 0.104 & -1.32 & -0.048 & 0.102 & -0.45 \\
\hline Sleep duration & & & & & & & 0.175 & 0.026 & $6.73^{* * * *}$ & 0.133 & 0.027 & $4.93^{* * * *}$ \\
\hline Detachment & & & & & & & & & & 0.038 & 0.039 & 0.97 \\
\hline Relaxation & & & & & & & & & & 0.049 & 0.035 & 1.47 \\
\hline Mastery experiences & & & & & & & & & & 0.079 & 0.036 & $2.22^{*}$ \\
\hline Sleep quality & & & & & & & & & & 0.196 & 0.045 & $4.31^{* * * *}$ \\
\hline$-2 \times \log (\mathrm{lh})$ & \multirow{3}{*}{\multicolumn{3}{|c|}{927.574}} & \multicolumn{3}{|c|}{883.049} & \multicolumn{3}{|c|}{840.207} & \multicolumn{3}{|c|}{814.379} \\
\hline Difference of $-2 \times \log$ & & & & \multicolumn{3}{|c|}{$44.525^{* * *}$} & \multicolumn{3}{|c|}{$42.842^{* * * *}$} & \multicolumn{3}{|c|}{$25.828^{* * * *}$} \\
\hline$d f$ & & & & \multicolumn{3}{|c|}{5} & \multicolumn{3}{|c|}{3} & \multicolumn{3}{|c|}{4} \\
\hline Level 1 intercept variance $(S E)$ & \multicolumn{3}{|c|}{$0.275(0.023)$} & \multirow{2}{*}{\multicolumn{3}{|c|}{$\begin{array}{l}0.275(0.023) \\
0.264(0.042)\end{array}$}} & \multirow{2}{*}{\multicolumn{3}{|c|}{$\begin{array}{l}0.242(0.020) \\
0.263(0.041)\end{array}$}} & \multirow{2}{*}{\multicolumn{3}{|c|}{$\begin{array}{l}0.221(0.019) \\
0.268(0.041)\end{array}$}} \\
\hline Level 2 intercept variance $(S E)$ & \multicolumn{3}{|c|}{$0.385(0.056)$} & & & & & & & & & \\
\hline
\end{tabular}

${ }^{*} p<.05 .{ }^{* * * *} p<.001$.

Taken together, Hypothesis 1, which predicted a relation between lack of psychological detachment and negative activation and fatigue, was supported. Hypothesis 2, which predicted relations between relaxation and affective outcomes, was supported for serenity but not for positive activation. Hypothesis 3, which specified relations between mastery experiences and affective outcomes, received support for positive activation but not for serenity. Sleep quality predicted all affect measures, thus lending support for Hypotheses 4 and 5. Across all analyses, sleep quality was the strongest predictor of morning affect.

\section{Additional Analyses}

One might argue that sleep quality mediates the relation between evening recovery experiences and morning affect. For example, the inability to detach psychologically from one's job

Table 3

Multilevel Estimates for Models Predicting Morning Serenity

\begin{tabular}{|c|c|c|c|c|c|c|c|c|c|c|c|c|}
\hline \multirow[b]{2}{*}{ Variable } & \multicolumn{3}{|c|}{ Null model } & \multicolumn{3}{|c|}{ Model 1} & \multicolumn{3}{|c|}{ Model 2} & \multicolumn{3}{|c|}{ Model 3} \\
\hline & Estimate & $S E$ & $t$ & Estimate & $S E$ & $t$ & Estimate & $S E$ & $t$ & Estimate & $S E$ & $t$ \\
\hline Intercept & 3.296 & 0.053 & 62.19 & 2.873 & 0.241 & 11.92 & 2.879 & 0.229 & 12.57 & 2.870 & 0.232 & 12.37 \\
\hline Gender & & & & -0.035 & 0.111 & -0.32 & -0.021 & 0.105 & -0.20 & -0.025 & 0.107 & -0.23 \\
\hline Age & & & & 0.002 & 0.005 & 0.40 & 0.002 & 0.004 & 0.50 & 0.003 & 0.005 & 0.60 \\
\hline Country & & & & 0.245 & 0.114 & $2.15^{*}$ & 0.239 & 0.108 & $2.21^{*}$ & 0.229 & 0.109 & $2.10^{*}$ \\
\hline Position & & & & 0.074 & 0.118 & 0.63 & 0.054 & 0.112 & 0.48 & 0.065 & 0.114 & 0.57 \\
\hline Trait serenity & & & & 0.438 & 0.067 & $6.54^{* * * *}$ & 0.382 & 0.073 & $5.23^{* * * *}$ & 0.407 & 0.073 & $5.57^{\text {*** }}$ \\
\hline Serenity previous morning & & & & & & & 0.089 & 0.054 & 1.65 & 0.051 & 0.053 & 0.96 \\
\hline Daily hassles & & & & & & & -0.086 & 0.116 & -0.74 & 0.014 & 0.114 & 0.12 \\
\hline Sleep duration & & & & & & & 0.157 & 0.030 & $5.23^{* * *}$ & 0.123 & 0.031 & $3.97^{* * * *}$ \\
\hline Detachment & & & & & & & & & & 0.066 & 0.044 & 1.50 \\
\hline Relaxation & & & & & & & & & & 0.083 & 0.039 & $2.13^{*}$ \\
\hline Mastery experiences & & & & & & & & & & 0.071 & 0.041 & 1.73 \\
\hline Sleep quality & & & & & & & & & & 0.162 & 0.050 & $3.24^{* *}$ \\
\hline$-2 \times \log (\mathrm{lh})$ & \multirow{3}{*}{\multicolumn{3}{|c|}{958.464}} & & \multicolumn{3}{|c|}{885.525} & \multicolumn{3}{|c|}{864.094} \\
\hline Difference of $-2 \times \log$ & & & & \multicolumn{3}{|c|}{$43.267^{* * * *}$} & \multicolumn{3}{|c|}{$29.67^{* * * *}$} & \multicolumn{3}{|c|}{$21.431^{* * * *}$} \\
\hline$d f$ & & & & \multicolumn{3}{|r|}{5} & \multicolumn{3}{|r|}{3} & \multicolumn{3}{|r|}{4} \\
\hline Level 1 intercept variance $(S E)$ & \multirow{2}{*}{\multicolumn{3}{|c|}{$0.328(0.028)$}} & \multicolumn{3}{|c|}{$0.328(0.028)$} & \multicolumn{3}{|c|}{$0.313(0.026)$} & \multicolumn{3}{|c|}{$0.286(0.024)$} \\
\hline Level 2 intercept variance $(S E)$ & & & & \multicolumn{3}{|c|}{$0.205(0.039)$} & \multicolumn{3}{|c|}{$0.177(0.035)$} & \multicolumn{3}{|c|}{$0.195(0.035)$} \\
\hline
\end{tabular}

${ }^{*} p<.05 .{ }^{* * *} p<.01{ }^{* * * *} p<.001$. 
Table 4

Multilevel Estimates for Models Predicting Morning Negative Activation

\begin{tabular}{|c|c|c|c|c|c|c|c|c|c|c|c|c|}
\hline \multirow[b]{2}{*}{ Variable } & \multicolumn{3}{|c|}{ Null model } & \multicolumn{3}{|c|}{ Model 1} & \multicolumn{3}{|c|}{ Model 2} & \multicolumn{3}{|c|}{ Model 3} \\
\hline & Estimate & $S E$ & $t$ & Estimate & $S E$ & $t$ & Estimate & $S E$ & $t$ & Estimate & $S E$ & $t$ \\
\hline Intercept & 1.232 & 0.024 & 51.33 & 1.199 & 0.112 & 10.71 & 1.205 & 0.111 & 10.86 & 1.205 & 0.108 & 11.16 \\
\hline Gender & & & & -0.008 & 0.051 & -0.16 & -0.009 & 0.051 & 0.18 & -0.016 & 0.050 & -0.32 \\
\hline Age & & & & 0.003 & 0.003 & 1.00 & 0.003 & 0.002 & 1.50 & 0.003 & 0.002 & 1.50 \\
\hline Country & & & & -0.087 & 0.053 & -1.64 & -0.091 & 0.053 & -1.72 & -0.076 & 0.051 & -1.49 \\
\hline Position & & & & 0.024 & 0.055 & 0.44 & 0.023 & 0.055 & 0.42 & 0.027 & 0.053 & 0.51 \\
\hline Trait negative activation & & & & 0.213 & 0.037 & $5.76^{* * *}$ & 0.212 & 0.046 & $4.61^{* * * *}$ & 0.193 & 0.045 & $4.11^{* * * *}$ \\
\hline $\begin{array}{l}\text { Negative activation previous } \\
\text { morning }\end{array}$ & & & & & & & 0.000 & 0.049 & 0.00 & 0.019 & 0.047 & 0.40 \\
\hline Daily hassles & & & & & & & 0.183 & 0.078 & $2.35^{*}$ & 0.111 & 0.076 & 1.46 \\
\hline Sleep duration & & & & & & & -0.020 & 0.020 & -1.00 & 0.026 & 0.021 & 1.24 \\
\hline Detachment & & & & & & & & & & -0.068 & 0.029 & $-2.34^{*}$ \\
\hline Relaxation & & & & & & & & & & -0.022 & 0.026 & -0.85 \\
\hline Mastery experiences & & & & & & & & & & -0.010 & 0.027 & -0.37 \\
\hline Sleep quality & & & & & & & & & & -0.199 & 0.034 & $-5.85^{* * *}$ \\
\hline$-2 \times \log (\mathrm{lh})$ & \multirow{3}{*}{\multicolumn{3}{|c|}{497.789}} & \multicolumn{3}{|c|}{461.894} & \multicolumn{3}{|c|}{455.768} & \multicolumn{3}{|c|}{414.608} \\
\hline Difference of $-2 \times \log$ & & & & \multicolumn{3}{|c|}{$35.895^{* * *}$} & \multicolumn{3}{|r|}{6.126} & \multicolumn{3}{|c|}{$41.16^{* * *}$} \\
\hline$d f$ & & & & \multicolumn{3}{|c|}{5} & \multicolumn{3}{|r|}{3} & \multicolumn{3}{|c|}{4} \\
\hline Level 1 intercept variance $(S E)$ & \multirow{2}{*}{\multicolumn{3}{|c|}{$0.156(0.013)$}} & \multicolumn{3}{|c|}{$0.154(0.013)$} & \multirow{2}{*}{\multicolumn{3}{|c|}{$0.152(0.013)$}} & \multicolumn{3}{|c|}{$0.135(0.011)$} \\
\hline Level 2 intercept variance $(S E)$ & \multicolumn{2}{|c|}{$0.029(0.011)$} & & \multicolumn{3}{|c|}{$0.014(0.009)$} & & & $0.014(0.009)$ & \multicolumn{3}{|c|}{$0.016(0.008)$} \\
\hline
\end{tabular}

${ }^{*} p<.05 .{ }^{* * * *} p<.001$.

during the evening might impede sleep quality (Akerstedt et al., 2002), which in turn affects morning affect. We started the statistical test of such a mediator effect by first examining whether recovery experiences predicted sleep quality (Baron \& Kenny, 1986). Hierarchical linear modeling, with sleep quality as the outcome variable and recovery experiences as predictor variables, revealed no significant effect for any of the three recovery experience variables. Therefore, our data do not support the idea that sleep quality mediates the relation between recovery experiences and morning affect.

\section{Discussion}

Edwards and Rothbard (2000) have argued that affect experienced in one life domain spills over into the other domain, implying that affect at home matters for affect at work. Although

Table 5

Multilevel Estimates for Models Predicting Morning Fatigue

\begin{tabular}{|c|c|c|c|c|c|c|c|c|c|c|c|c|}
\hline \multirow[b]{2}{*}{ Variable } & \multicolumn{3}{|c|}{ Null model } & \multicolumn{3}{|c|}{ Model 1} & \multicolumn{3}{|c|}{ Model 2} & \multicolumn{3}{|c|}{ Model 3} \\
\hline & Estimate & $S E$ & $t$ & Estimate & $S E$ & $t$ & Estimate & $S E$ & $t$ & Estimate & $S E$ & $t$ \\
\hline Intercept & 1.863 & 0.053 & 35.15 & 1.986 & 0.239 & 8.31 & 1.986 & 0.226 & 8.79 & 1.998 & 0.231 & 8.65 \\
\hline Gender & & & & 0.158 & 0.111 & 1.42 & 0.143 & 0.104 & 1.38 & 0.143 & 0.106 & 1.35 \\
\hline Age & & & & -0.008 & 0.005 & -1.60 & -0.007 & 0.004 & -1.75 & -0.008 & 0.005 & -1.60 \\
\hline Country & & & & 0.058 & 0.113 & 0.51 & 0.048 & 0.107 & 0.45 & 0.070 & 0.109 & 0.64 \\
\hline Position & & & & -0.085 & 0.117 & -0.73 & -0.069 & 0.111 & -0.62 & -0.083 & 0.113 & -0.73 \\
\hline Trait fatigue & & & & 0.408 & 0.055 & $7.42^{* * *}$ & 0.345 & 0.065 & $5.31^{* * * * *}$ & 0.386 & 0.064 & $6.03^{* * * *}$ \\
\hline Fatigue previous morning & & & & & & & 0.091 & 0.058 & 1.57 & 0.027 & 0.054 & 0.50 \\
\hline Daily hassles & & & & & & & 0.187 & 0.127 & 1.42 & 0.055 & 0.119 & 0.46 \\
\hline Sleep duration & & & & & & & -0.161 & 0.032 & $-5.03^{* * *}$ & -0.079 & 0.032 & $-2.47^{* *}$ \\
\hline Detachment & & & & & & & & & & -0.112 & 0.046 & $-2.43^{* *}$ \\
\hline Relaxation & & & & & & & & & & 0.009 & 0.041 & 0.22 \\
\hline Mastery experiences & & & & & & & & & & -0.068 & 0.043 & -1.66 \\
\hline Sleep quality & & & & & & & & & & -0.360 & 0.053 & $-6.79^{* * *}$ \\
\hline$-2 \times \log (\mathrm{lh})$ & \multirow{3}{*}{\multicolumn{3}{|c|}{1019.416}} & \multicolumn{3}{|c|}{965.343} & \multicolumn{4}{|c|}{939.124} & \multicolumn{2}{|c|}{887.415} \\
\hline Difference of $-2 \times \log$ & & & & \multicolumn{3}{|c|}{$54.073^{* * * *}$} & \multicolumn{3}{|c|}{$26.219^{* * * *}$} & \multicolumn{3}{|c|}{$51.709^{\text {**** }}$} \\
\hline$d f$ & & & & \multicolumn{3}{|c|}{5} & \multicolumn{3}{|c|}{3} & \multicolumn{3}{|c|}{4} \\
\hline Level 1 intercept variance $(S E)$ & \multicolumn{3}{|c|}{$0.401(0.034)$} & \multirow{2}{*}{\multicolumn{3}{|c|}{$\begin{array}{l}0.394(0.033) \\
0.175(0.038)\end{array}$}} & \multirow{2}{*}{\multicolumn{3}{|c|}{$\begin{array}{l}0.383(0.032) \\
0.144(0.034)\end{array}$}} & \multirow{2}{*}{\multicolumn{3}{|c|}{$\begin{array}{l}0.313(0.026) \\
0.181(0.036)\end{array}$}} \\
\hline Level 2 intercept variance $(S E)$ & \multicolumn{3}{|c|}{$0.291(0.052)$} & & & & & & & & & \\
\hline
\end{tabular}

${ }^{* * *} p<.01 .^{* * * *} p<.001$. 
experience-sampling studies have provided increasing evidence that affect at home is related to affect subsequently experienced at work (Judge \& Ilies, 2004; Williams \& Alliger, 1994), little research attention has been paid to factors that may influence morning affect. Our study addressed this gap in the literature and focused on recovery experiences and sleep quality as predictors of morning affect. Analyses showed that evening recovery experiences and sleep quality predicted affect in the morning before going to work. Low psychological detachment from work during the evening was related to fatigue and high negative activation in the morning, whereas relaxation and mastery experiences were related to morning serenity and morning positive activation, respectively. Good sleep quality predicted all morning affect variables. Our study contributes to knowledge on job-stress recovery and affect regulation by demonstrating which specific experiences in the home domain are related to affect at the transition point to the work domain. By focusing on specific experiences, our study is explicit about the experiences that employees may look for to improve positive, and reduce negative, affect.

Low psychological detachment from work predicted morning negative activation and fatigue, suggesting that psychological detachment is a powerful recovery experience. Earlier research has shown that psychological detachment is related to affect assessed during the same evening (Sonnentag \& Bayer, 2005). This study demonstrates that psychological detachment also matters for affect experienced in the next morning. Thus, although it is highly important to engage oneself into the work process when being at work (Britt, Castro, \& Adler, 2005; Schaufeli \& Bakker, 2004), temporarily detaching oneself from work during off-job time seems to have benefits as well.

Relaxation, a recovery experience associated with low activation, was related to morning serenity but not to morning positive activation. Mastery, with its focus on learning and facing challenges, is an experience associated with high activation. It was found to be positively related to morning positive activation but not to morning serenity. Thus, the degree of activation associated with the recovery experiences and the activation level of the affect variables correspond closely.

Sleep quality was the strongest predictor of all affect variables. This result is in line with earlier findings that demonstrated a substantial relation between sleep quality and subsequent affect (Scott \& Judge, 2006; Totterdell et al., 1994). Recovery experiences, however, did not predict sleep quality. It might be that other factors (e.g., food and alcohol intake during the evening, a child needing attention during the night, or outside noise) have a greater impact on sleep quality than the recovery experiences examined. Moreover, absolute (i.e., noncentered) levels of psychological detachment were relatively high $(M=3.86)$. It might be that sleep quality becomes impaired only at extremely low levels of detachment.

Although our core findings that evening recovery experiences and sleep predict morning affect might appear like common sense, it is necessary to put such wide-spread assumptions to an empirical test (e.g., recovery experiences did not predict sleep quality). Moreover, our rather specific pattern of findings, with lack of psychological detachment being related to negative activation and fatigue, and relaxation and mastery experiences being related to serenity and positive activation, respectively, goes beyond what one might predict from everyday experience.

\section{Study Limitations}

This study has some limitations. First, we assessed all data with self-report measures raising concerns about common-method variance (Podsakoff, MacKenzie, Lee, \& Podsakoff, 2003). By using person-centered scores in the analyses, we eliminated the potential influence of response tendencies stemming from individual differences (e.g., negative affectivity), and we thereby reduced the problems associated with common-method data. Future studies might include reports of significant others in the analyses. Although it would have been preferable to have an objective sleep quality measure, the subjective reports are probably not a major cause of concern, as research has shown that subjective ratings of sleep quality closely correspond to objective measures (Akerstedt, Hume, Minors, \& Waterhouse, 1994).

Second, sleep quality was assessed concurrently with morning affect. Therefore, we cannot rule out that momentary affect in the morning influenced sleep quality ratings. Similarly, respondents' momentary evening affect might have influenced their recovery ratings, and mainly evening affect might have accounted for the relation between recovery experience and morning affect (cf. Judge \& Ilies, 2004). Again, using reports provided by significant others could overcome this problem in future studies.

A third limitation refers to our sample of public service employees working relatively regular hours. Of course, it is desirable to replicate our results with samples from different employment contexts and with samples working less regular (and maybe longer) hours. However, we believe that our findings have some degree of generalizability, as we sampled employees with various professional backgrounds from different organizations in two countries.

Fourth, within-person variance explained by the study variables ranged between 12.8 and 21.9. Although these percentages might appear small, they are similar to findings from studies that predicted affect at work (Fisher \& Noble, 2004; Zohar et al., 2003).

\section{Directions for Future Research and Implications for Practice}

In our study, we focused on the relation between recovery experiences and sleep on the one hand and morning affect on the other hand. It is a particular important question for future researchers to examine whether and how the effects of these nonwork experiences unfold during work. For example, it would be interesting to know how long the effects of recovery experiences "survive" during the subsequent working day and when they fade out.

Another important goal for future research will be to establish causality between recovery experiences and subsequent affect. Although our study design ruled out many of the pitfalls of cross-sectional research, we cannot be sure that for instance low psychological detachment caused fatigue. We suggest using experimental designs to test causality between recovery and affect. Promising options include interrupted time series analysis (Velicer \& Fava, 2003) and long-term intervention studies (Van der Klink et al., 2001).

Overall, the strain level in our sample was not very high. Therefore, future studies should examine whether our findings also hold for persons experiencing high levels of strain. On the one 
hand, one might argue that recovery becomes particularly important when strain levels are elevated. On the other hand, however, it could also be that the relatively short time periods available for daily recovery are not sufficient when persons experience high levels of strain.

Our study has practical implications. Assuming that recovery experiences and sleep quality at least partially contribute to affect in a causal way, it is important to enable employees to switch off from work when being at home (e.g., by deliberately segmenting work and off-job life; Rothbard, Philips, \& Dumas, 2005) and to engage in activities that provide opportunities for relaxation and mastery experiences. Sleep quality could be improved by sleep hygiene measures, such as going to bed at regular times and by not drinking alcohol or caffeine beverages before going to sleep (Mastin, Bryson, \& Corwyn, 2006).

Recovery experiences showed specific relations with affect measures. In practical terms, our findings imply that the goal of promoting positive activation requires another recovery experience (namely mastery experiences) than the goal of avoiding negative activation and fatigue (namely psychological detachment). Thus, for achieving positive activation and serenity in the morning, it does not help to detach oneself from work during off-job time but to engage in mastery experiences or relaxation.

\section{References}

Abele-Brehm, A., \& Brehm, W. (1986). Zur Konzeptualisierung und Messung von Befindlichkeit: Die Entwicklung der "Befindlichkeitsskalen" (BFS) [Conceptualizing and assessing affect: The development of the "Befindlichkeitsskalen" (BFS)]. Diagnostica, 32, 209-228.

Akerstedt, T., Hume, K., Minors, D., \& Waterhouse, J. (1994). The meaning of good sleep: A longitudinal study of polysomnography and subjective sleep quality. Journal of Sleep Research, 3, 152-158.

Akerstedt, T, Knutsson, A., Westerholm, P., Theorell, T., Alfredsson, L., \& Kecklund, G. (2002). Sleep disturbances, work stress and work hours: A cross-sectional study. Journal of Psychosomatic Research, 53, 741-748.

Baron, R. M., \& Kenny, D. A. (1986). The moderator-mediator variable distinction in social psychological research: Conceptual, strategic and statistical considerations. Journal of Personality and Social Psychology, 51, 1173-1182.

Benson, H. (1975). The relaxation response. New York: Morrow.

Binnewies, C., Sonnentag, S., \& Mojza, E. J. (2006, August). The power of recovery: It is not only good for the person, it is good for performance. Paper presented at the Academy of Management Meeting, Atlanta, GA.

Bolger, N., Davis, A., \& Rafaeli, E. (2003). Diary methods: Capturing life as it is lived. Annual Review of Psychology, 54, 579-616.

Britt, T. W., Castro, C. A., \& Adler, A. B. (2005). Self engagement, stressors, and health: A longitudinal study. Personality and Social Psychology Bulletin, 31, 1475-1486.

Brosschott, J. F., Gerin, W., \& Thayer, J. F. (2006). The perseverative cognition hypothesis: A review of worry, prolonged stress-related activation, and health. Journal of Psychosomatic Research, 60, 113-124.

Bryk, A. S., \& Raudenbush, S. W. (1992). Hierarchical linear models: Application and data analysis methods. Newbury Park, CA: Sage.

Buysse, D. J., Reynolds, C. F., Monk, T. H., Berman, S. R., \& Kupfer, D. J. (1989). Pittsburgh Sleep Quality Index (PSQI). Psychiatry Research, 28, 193-213.

Cacioppo, J. T., \& Gardner, W. L. (1999). Emotion. Annual Review of Psychology, 50, 191-214.

Crouter, A. C. (1984). Spillover from family to work: The neglected side of the work-family interface. Human Relations, 37, 425-442.

Edwards, J. R., \& Rothbard, N. P. (2000). Mechanisms linking work and family: Clarifying the relationship between work and family constructs. Academy of Management Review, 25, 178-199.

Etzion, D., Eden, D., \& Lapidot, Y. (1998). Relief from job stressors and burnout: Reserve service as a respite. Journal of Applied Psychology, 83, $577-585$.

Fisher, C. D. (2002). Antecedents and consequences of real-time affective reactions at work. Motivation and Emotion, 26, 3-30.

Fisher, C. D., \& Noble, C. S. (2004). A within-person examination of correlates of performance and emotions while working. Human Performance, 17, 145-168.

Ford, M. T., Heinen, B. A., \& Langkamer, K. L. (2007). Work and family satisfaction and conflict: A meta-analysis of cross-domain relations. Journal of Applied Psychology, 92, 57-80.

Frankenhaueser, M., \& Johansson, G. (1986). Stress at work: Psychobiological and psychosocial aspects. International Review of Applied Psychology, 35, 287-299.

Fredrickson, B. (2000). Cultivating positive emotions to optimize health and well-being. Prevention \& Treatment, 3(1).

Fritz, C., \& Sonnentag, S. (2005). Recovery, health, and job performance: Effects of weekend experiences. Journal of Occupational Health Psychology, 10, 187-199.

Fritz, C., \& Sonnentag, S. (2006). Recovery, well-being, and performancerelated outcomes: The role of workload and vacation experiences. Journal of Applied Psychology, 91, 936-945.

Fuller, J. A., Stanton, J. M., Fisher, G. G., Spitzmüller, C., Russell, S. S., \& Smith, P. C. (2003). A lengthy look at the daily grind: Time series analyses of events, mood, stress, and satisfaction. Journal of Applied Psychology, 88, 1019-1033.

Gable, S. L., Reis, H. T., \& Elliot, A. J. (2000). Behavioral activation and inhibition in everyday life. Journal of Personality and Social Psychology, 78, 1135-1149.

Geurts, S. A. E., \& Sonnentag, S. (2006). Recovery as an explanatory mechanism in the relation between acute stress reactions and chronic health impairment. Scandinavian Journal of Work, Environment and Health, 32, 482-492.

Greenhaus, J. H., \& Powell, G. N. (2006). When work and family are allies: A theory of work-family enrichment. Academy of Management Journal, 31, 72-92.

Grossman, P., Niemann, L., Schmidt, S., \& Walach, H. (2004). Mindfulness-based stress reduction and health benefits: A meta-analysis. Journal of Psychosomatic Research, 57, 35-43.

Harris, C., \& Daniels, K. (2005). Daily affect and daily beliefs. Journal of Occupational Health Psychology, 10, 415-428.

Hartig, T., Evans, G. W., Jamner, L. D., Davis, D. S., \& Gärling, T. (2003). Tracking restoration in natural and urban field settings. Journal of Environmental Psychology, 23, 109-123.

Heller, D., \& Watson, D. (2005). The dynamic spillover of satisfaction between work and marriage: The role of time and mood. Journal of Applied Psychology, 90, 1273-1279.

Hobfoll, S. E. (1998). Stress, culture, and community: The psychology and physiology of stress. New York: Plenum.

Jacobson, E. (1938). Progressive relaxation. Chicago: University of Chicago Press.

Judge, T. A., \& Ilies, R. (2004). Affect and job satisfaction: A study of their relationship at work and at home. Journal of Applied Psychology, 89, 661-673.

Judge, T. A., Ilies, R., \& Scott, B. A. (2006). Work-family conflict and emotions: Effects at work and at home. Personnel Psychology, 59, 779-814.

Kanner, A. D., Coyne, J. C , Schaefer, C., \& Lazarus, R. S. (1981). Comparison of two modes of stress measurement: Daily hassles and uplifts versus major life events. Journal of Behavioral Medicine, 4, 1-39.

Lavidor, M., Weller, A., \& Babkoff, H. (2003). How sleep is related to fatigue. British Journal of Health Psychology, 8, 95-105. 
Mastin, D. F., Bryson, J., \& Corwyn, R. (2006). Assessment of sleep hygiene using the sleep hygiene index. Journal of Behavioral Medicine, 29, 223-227.

McNair, D. M., Lorr, M., \& Droppelman, L. F. (1971). Edits manual for the profile of mood states. San Diego, CA: Educational and Industrial Testing Service.

Meijman, T. F., \& Mulder, G. (1998). Psychological aspects of workload. In P. J. D. Drenth \& H. Thierry (Eds.), Handbook of work and organizational psychology: Work psychology (Vol. 2, pp. 5-33). Hove, England: Psychology Press.

Muraven, M., \& Baumeister, R. F. (2000). Self-regulation and depletion of limited resources: Does self-control resemble a muscle? Psychological Bulletin, 126, 247-259.

Parkinson, B., \& Totterdell, P. (1999). Classifying affect-regulation strategies. Cognition and Emotion, 13, 277-303.

Pelletier, C. L. (2004). The effect of music on decreasing arousal due to stress: A meta-analysis. Journal of Music Therapy, 41, 192-214.

Pilcher, J. J., Ginter, D. R., \& Sadowsky, B. (1997). Sleep quality versus sleep quantity: Relationships between sleep and measures of health, well-being and sleepiness in college students. Journal of Psychosomatic Research, 42, 583-596.

Pilcher, J. J., \& Huffcutt, A. I. (1996). Effects of sleep deprivation on performance: A meta-analysis. Sleep, 19, 318-326.

Podsakoff, P. M., MacKenzie, S. B., Lee, J.-Y., \& Podsakoff, N. P. (2003). Common method biases in behavioral research: A critical review of the literature and recommended remedies. Journal of Applied Psychology, 88, 879-903.

Rasbash, J., Browne, W., Goldstein, H., Yang, M., Plewis, I., Healy, M., et al. (2000). A user's guide to MLwiN. London: Multilevel Models Project Institute of Education, University of London.

Rook, J. W., \& Zijlstra, F. R. H. (2006). The contribution of various types of activities to recovery. European Journal of Work and Organizational Psychology, 15, 218-240.

Rothbard, N. P. (2001). Enriching or depleting? The dynamics of engagement in work and family roles. Administrative Science Quarterly, 46, $655-684$.

Rothbard, N. P., Philips, K. W., \& Dumas, T. L. (2005). Managing multiple roles: Work-family policies and individuals' desires for segmentation. Organization Science, 16, 243-258.

Ruderman, M. N., Ohlott, P. J., Panzer, K., \& King, S. N. (2002). Benefit of multiple roles for managerial women. Academy of Management Journal, 45, 369-386.

Russell, J. A. (1980). A circumplex model of affect. Journal of Personality and Social Psychology, 39, 1161-1178.

Russell, J. A., \& Carroll, J. M. (1999). On the bipolarity of positive and negative affect. Psychological Bulletin, 125, 3-30.

Sandlung, E. S., \& Norlander, T. (2000). The effects of Tai Chi Chuan relaxation and exercise on stress responses and well-being: An overview of research. International Journal of Stress Management, 7, 139-149.

Schaufeli, W. B., \& Bakker, A. B. (2004). Job demands, job resources, and their relationship with burnout and engagement: A multi-sample study. Journal of Organizational Behavior, 25, 293-315.

Scott, B. A., \& Judge, T. A. (2006). Insomnia, emotions, and job satisfaction: A multilevel study. Journal of Management, 32, 622-645.

Snijders, T. A. B., \& Bosker, R. J. (1999). Multilevel analysis: An introduction to basic and advanced multilevel modeling. London: Sage.

Sonnentag, S. (2001). Work, recovery activities, and individual well-being: A diary study. Journal of Occupational Health Psychology, 6, 196-210. Sonnentag, S., \& Bayer, U.-V. (2005). Switching off mentally: Predictors and consequences of psychological detachment from work during offjob time. Journal of Occupational Health Psychology, 10, 393-414.

Sonnentag, S., \& Fritz, C. (2007). The Recovery Experience Questionnaire: Development and validation of a measure assessing recuperation and unwinding at work. Journal of Occupational Health Psychology, 12, 204-221.

Sonnentag, S., \& Zijlstra, F. R. H. (2006). Job characteristics and off-job activities as predictors of need for recovery, well-being, and fatigue. Journal of Applied Psychology, 91, 330-350.

Stone, A. A., Kennedy-Moore, E., \& Neale, J. M. (1995). Association between daily coping and end-of-day mood. Health Psychology, 14, 341-349.

Strauss-Blasche, G., Ekmekcioglu, C., \& Marktl, W. (2000). Does vacation enable recuperation? Changes in well-being associated with time away from work. Occupational Medicine, 50, 167-172.

Thayer, R. E., Newman, J. R., \& McClain, T. M. (1994). Self-regulation of mood: Strategies for changing a bad mood, raising energy, and reducing tension. Journal of Personality and Social Psychology, 67, 910-925.

Totterdell, P., Reynolds, S., Parkinson, B., \& Briner, R. B. (1994). Associations of sleep with everyday mood, minor symptoms and social interaction experience. Sleep, 17, 466-475.

Totterdell, P., Wood, S., \& Wall, T. (2006). An intra-individual test of the demands-control model: A weekly diary study of psychological strain in portfolio workers. Journal of Occupational and Organizational Psychology, 79, 63-84.

Trougakos, J. P., Beal, D. J., Green, S. G., \& Weiss, H. M. (in press). Making the break count: An episodic examination of recovery activities, emotional experiences, and positive affective displays. Academy of Management Journal.

Van der Klink, J. J. L., Blonk, R. W. B., Schene, A. H., \& Van Dijk, F. J. H. (2001). The benefits of interventions for work-related stress. American Journal of Public Health, 91, 270-276.

Velicer, W. F., \& Fava, J. L. (2003). Time series analysis. In J. A. Schinka \& W. F. Velicer (Eds.), Handbook of psychology: Research methods in psychology (Vol. 2, pp. 581-606). Hoboken, NJ: Wiley.

Watson, D. (1988). Intraindividual and interindividual analyses of positive and negative affect: Their relation to health complaints, perceived stress, and daily activities. Journal of Personality and Social Psychology, 54, $1020-1030$.

Watson, D., \& Clark, L. A. (1994). The PANAS-X: Manual for the positive and negative affect schedule. Iowa City: University of Iowa.

Watson, D., Clark, L. A., \& Tellegen, A. (1988). Development and validation of brief measures of positive and negative affect: The PANAS scales. Journal of Personality and Social Psychology, 54, 1063-1070.

Watson, D., Wiese, D., Vaidya, J., \& Tellegen, A. (1999). The two general activation systems of affect: Structural findings, evolutionary considerations, and psychobiological evidence. Journal of Personality and Social Psychology, 76, 820-838.

Westman, M., \& Eden, D. (1997). Effects of a respite from work on burnout: Vacation relief and fade-out. Journal of Applied Psychology, $82,516-527$

Williams, K. J., \& Alliger, G. M. (1994). Role stressors, mood spillover, and perceptions of work-family conflict in employed parents. Academy of Management Journal, 37, 837-868.

Zohar, D., Tzischinski, O., \& Epstein, R. (2003). Effects of energy availability on immediate and delayed emotional reactions to work events. Journal of Applied Psychology, 88, 1082-1093.

Zohar, D., Tzischinski, O., Epstein, R., \& Lavie, P. (2005). The effects of sleep loss on medical residents' emotional reactions to work events: A cognitive-energy model. Sleep, 28, 47-54. 
Appendix

Recovery Experience Items

\begin{tabular}{ll}
\hline \multicolumn{1}{c}{ Measure } & \multicolumn{1}{c}{ Items } \\
\hline Psychological detachment & Tonight, I forgot about work. \\
& Tonight, I did not think about work at all. \\
& Tonight, I distanced myself from my work. \\
& Tonight, I got a break from the demands of work. \\
& Tonight, I kicked back and relaxed. \\
Relaxation & Tonight, I did relaxing things. \\
& Tonight, I used the time to relax. \\
& Tonight, I took time for leisure. \\
& Tonight, I learned new things. \\
Mastery experiences & Tonight, I looked for intellectual challenges. \\
& Tonight, I did things that challenge me. \\
& Tonight, I did something to broaden my horizons.
\end{tabular}

Konstanzer Online-Publikations-System (KOPS)

URL:

http://www.ub.uni-konstanz.de/kops/volltexte/2008/5650 I

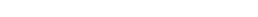

\section{American Psychological Association Subscription Claims Information}

Today's Date:

We provide this form to assist members, institutions, and nonmember individuals with any subscription problems. With the appropriate information we can begin a resolution. If you use the services of an agent, please do NOT duplicate claims through them and directly to us. PLEASE PRINT CLEARLY AND IN INK IF POSSIBLE.

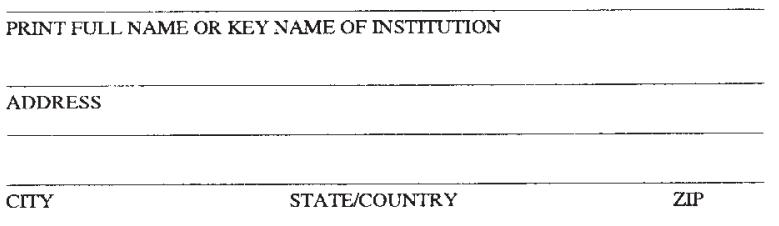

YOUR NAME AND PHONE NUMBER

TITLE
MEMBER OR CUSTOMER NUMBER (MAY BEFOUND ON ANY PAST ISSUE LABEL)

DATE YOUR ORDER WAS MAILED (OR PHONED)

_ PREPAID _ C CHECK _ CHARGE CHECK/CARD CLEARED DATE:

(If possible, send a copy, front and back, of your cancelled check to help us in our research of your claim.)

ISSUES: MISSING DAMAGED

VOLUME OR YEAR

NUMBER OR MONTH

Thank you. Once a claim is received and resolved, delivery of replacement issues routinely takes 4-6 weeks.

(TO BE FILLED OUT BY APA STAFF)

DATE RECEIVED:

ACTION TAKEN:

STAFF NAME:
DATE OF ACTION:

INV. NO. \& DATE:

LABEL NO. \& DATE:

Send this form to APA Subscription Claims, 750 First Street, NE, Washington, DC 20002-4242

PLEASE DO NOT REMOVE. A PHOTOCOPY MAY BE USED. 